\title{
EL PRECEDENTE JUDICIAL EN EL INTERPRETATIVISMO JURÍDICO DE RONALD DWORKIN
}

Judicial PRECEDENT in the legal interpretativism of RONALD DWORKIN

SANDRA GÓMORA-JUÁREZ ${ }^{1}$

Resumen: En el ámbito de la teoría jurídica, diversos autores han reflexionado acerca del papel del precedente en el razonamiento judicial. El modelo de principios es una forma de explicarlo y el interpretativismo jurídico de Ronald Dworkin es un ejemplo destacado. Este artículo reconstruye los elementos teóricos fundamentales implícitos y explícitos que estructuran el interpretativismo como propuesta teórica, a fin de explicar el concepto de precedente que contiene para identificar su alcance, posibilidades y finalmente, las potenciales preguntas que genera.

Palabras clave: Dworkin; interpretativismo jurídico; precedente; fuerza gravitacional; principios; razonamiento judicial.

Abstract: In legal theory, several authors have reflected on the role of precedent in judicial reasoning. The model of principles is one way to explain it and Ronald Dworkin's legal interpretivism is a prominent example of this model. This article reconstructs the fundamental implicit and explicit elements that structure interpretivism as a theoretical proposal, seeking to explain the concept of precedent it contains in order to identify its scope, possibilities and finally, the potential questions it poses.

${ }^{1}$ Doctora en derecho por el Instituto de Investigaciones Jurídicas de la UNAM, Investigadora Ordinaria de Carrera, Asociada C, T. C., en el Instituto de Investigaciones Jurídicas/UNAM. Contacto: <sgomoraj@unam.mx>. ORCID: <https://orcid. org/0000-0002-9164-6194>; WoS ResearcherID H-1322-2019.

Fecha de recepción: 26 de noviembre de 2020; fecha de aprobación: 09 de abril de 2021 . 
KeYwords: Dworkin; legal interpretivism; precedent; gravitational force; principles; judicial reasoning.

Sumario: I. Introducción; II. El precedente en el interpretativismo: los elementos implícitos; III. El precedente en el interpretativismo: los elementos explícitos; IV. Algunas conclusiones y nuevas preguntas. V. Referencias bibliográficas.

\section{INTROdUCción}

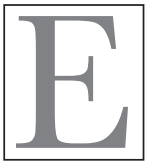

n el ámbito de la teoría jurídica, diversos autores han reflexionado acerca del alcance y la fuerza del precedente en el razonamiento judicial, entendiendo "precedente" como "la doctrina legal contenida en una sentencia que expresa la regla de juicio o la razón jurídica conforme a la cual se ha resuelto el caso".2 La discusión en torno a qué decisiones se ven afectadas por el precedente y las condiciones bajo las cuales obligan a los tribunales se puede entender de distintas maneras.

De acuerdo con Grant Lamond, hay tres formas principales en las que se ha teorizado acerca del concepto de precedente o, dicho de otro modo, tres formas que alegan ser la mejor forma de entender al precedente, su fuerza, alcance y papel en el razonamiento judicial: ${ }^{3}$

${ }^{2}$ Gascón Abellán, Marina, "Motivación de las sentencias y jurisprudencia. ¿Cumple nuestra jurisprudencia su función?, en Marina Gascón Abellán y Álvaro Núñez Vaquero (coords.), La construcción del precedente en el Civil Law, Barcelona, Atelier. Libros jurídicos, 2020, p. 166. Álvaro Núñez coincide en los elementos fundamentales de esta noción al caracterizar al precedente como "cualquier decisión de carácter jurisdiccional que expresa al menos una norma a la que se le dota de algún valor normativo para casos diferentes a aquel en cuyo contexto fue dictada", Núñez Vaquero, Álvaro, "Precedente en materia de hechos", Revista de derecho (Valdivia), Vol. 31, núm.1, julio 2018, consultado el 5 de julio de 2020 en: https://scielo.conicyt.cl/ scielo.php?script $=$ sci_arttext\&pid $=$ S07 18-09502018000100051\&lng $=$ es\&nrm $=$ iso.

${ }^{3}$ Lamond, Grant, "Precedent and Analogy in Legal Reasoning", The Stanford Encyclopedia of Philosophy (Spring 2016 Edition), Edward N. Zalta (ed.), URL $=<$ https:// plato.stanford.edu/archives/spr2016/entries/legal-reas-prec/>, consultado el 3 de 
como establecimiento de reglas; como aplicación de principios subyacentes y; como decisión del balance de razones.

El primer modelo trata a los precedentes como reglas que los tribunales posteriores están obligados a aplicar a los hechos que les presenta el caso que deciden. El segundo enfoque centra la atención en la justificación de la decisión pasada mediante principios, siendo éstos los de aplicación obligatoria. El tercer enfoque sugiere que es la representación de una decisión en el balance de razones de un caso individual lo que los tribunales posteriores han de tratar como decididos correctamente. ${ }^{4}$

A pesar de ser el más recurrido, el modelo de reglas no tiene una aceptación uniforme y ha sido objeto de diversas críticas. Una de las más importantes se halla en el trabajo de Ronald Dworkin denominado "el derecho como integridad" — que puede entenderse como un ejemplo del modelo 2- cuyo desarrollo ha ganado notoriedad al sugerir que las disputas deben resolverse con base en principios jurídicos. El derecho como integridad, considerado de suma importancia en el ámbito de la filosofía del derecho, ${ }^{5}$ contiene el desarrollo más sólido del modelo de precedente, razón por la cual merece una exploración detallada que identifique los elementos que lo componen.

En este artículo me propongo explicar el concepto de precedente en el interpretativismo jurídico de Ronald Dworkin, para lo cual haré una reconstrucción de los elementos teóricos fundamentales implícitos y explícitos que estructuran el interpretativismo como propuesta teórica, en la cual se inserta y de la cual deriva la concepción del precedente judicial. La interrelación de elementos

mayo de 2020. Para una explicación semejante con base en modelos, véase Alexander, Larry, "Los jueces como creadores de reglas", trad. de Sandra Gómora Juárez, Problema. Anuario de Filosofia y Teoría del Derecho, Núm. 4, 2010.

${ }^{4}$ Idem.

${ }^{5}$ Dickson, Julie, Evaluación en la teoría del derecho, trad. de Juan Vega Gómez, México, UNAM- Instituto de Investigaciones Jurídicas, 2006, p. 120. 
como la interpretación, las etapas interpretativas y los principios, entre otros, dan cuenta de la concepción interpretativista del precedente que plantea desafíos y preguntas que conviene explorar a lo largo del texto, en vista de que la aceptación del modelo no es pacífica.

\section{EL PRECEDENTE EN EL INTERPRETATIVISMO: LOS ELEMENTOS IMPLÍ́CITOS}

Comienzo ofreciendo una definición básica pero concreta del concepto de precedente en términos de la teoría jurídica de Ronald Dworkin, extraída de sus ideas desarrolladas, principalmente en Law's Empire. La definición propuesta señala que un precedente es el reporte de una decisión política previa que ejerce una fuerza gravitacional sobre casos futuros en la medida en la que se fundamenta en principios y en los términos de la extensión de tales principios.

El concepto de precedente sugerido contiene elementos que requieren mayor explicación desde la perspectiva original para comprenderlos en su justa dimensión, pero, además, debemos considerar que de estos elementos se desprenden un buen número de consecuencias e implicaciones concretas para la concepción del precedente que se derivan del particular enfoque teórico de la teoría del derecho como interpretación.

En ese sentido, la definición de precedente que propongo, extraída de la teoría interpretativista, contempla los siguientes elementos explícitos: el carácter de las sentencias judiciales como decisiones políticas; la cualidad de que decisiones judiciales previas ejerzan una fuerza gravitacional sobre casos futuros; el papel de la interpretación y los acuerdos compartidos; así como la noción de paradigma.

Simultáneamente, la definición ofrecida tiene ciertos elementos implícitos que debemos desarrollar y entender para estar en 
posibilidad de formar un juicio respecto de los méritos de esta concepción del precedente como ejemplar del modelo de principios. Los elementos implícitos a los que me refiero son la calidad de ser un concepto interpretativo; los aspectos que componen la interpretación constructiva; el papel de los principios en el razonamiento judicial, así como la tarea judicial en el derecho como integridad, principalmente.

En ese sentido, haré una revisión del conjunto de elementos implícitos en la explicación del concepto de precedente que brindan las herramientas necesarias para analizar posteriormente sus elementos explícitos.

1. El derecho y el precedente como conceptos INTERPRETATIVOS

De acuerdo con Ronald Dworkin, existen ciertos conceptos cuya naturaleza solo puede ser comprendida "interpretativamente", esto les otorga el carácter de conceptos evaluativos y la forma más práctica de comprenderlos es a través de la idea del "punto o propósito" al que sirven. El derecho es un concepto interpretativo. ${ }^{6}$

El derecho, como otras prácticas sociales se guían por propósitos, explica Dworkin. La interpretación del derecho es creativa y constructiva, al ser así, la interpretación constructiva de las prácticas sociales se ocupa de los propósitos de la práctica que se interpreta, fundamentalmente de los propósitos que el intérprete de la práctica advierte en ella. ${ }^{7}$

Los conceptos interpretativos tienen - en el pensamiento y en el discurso ordinario - un valor intrínseco que podemos conocer a través de la asignación del sentido que mejor capture ese valor, el

${ }^{6}$ Guest, Stephen, Ronald Dworkin, 3rd ed., Stanford University Press, California, 2013, p. 66.

${ }^{7}$ Dworkin Ronald, Law's Empire, Cambridge, Mass., Belknap-Harvard University Press, 1986, pp. 51-52. 
sentido que muestre de mejor manera qué es lo moralmente valioso de ese concepto para nosotros, eso significa mostrarlo desde su mejor perspectiva. ${ }^{8}$

Es por ello que, aunque se quiera, no podemos separar o aislar lo valioso de los conceptos interpretativos porque su importancia radica en ese valor integrado que tienen y que nosotros advertimos; son valiosos porque enriquecen nuestra vida de diferentes formas $\mathrm{y}$ tienen consecuencias positivas en nuestras vidas, individual y colectivamente. Ese aspecto normativo (lo bueno de los conceptos) es lo que se pretende explicar desde este enfoque. ${ }^{9}$

Para Dworkin, conceptos como el derecho, el precedente, la justicia, la libertad, y la cortesía son conceptos interpretativos. El derecho - desde esta perspectiva- es un concepto normativo porque tiene en sí mismo un valor moral para nosotros y es también interpretativo porque su explicación se desprende de la interpretación de otros conceptos normativos e interpretativos con los cuales se interrelaciona. ${ }^{10}$

$\mathrm{Al}$ tener un valor intrínseco, el análisis de los conceptos interpretativos (como derecho, precedente, igualdad o libertad) no puede surgir desde un enfoque moralmente neutral y puramente descriptivo porque se malinterpreta su verdadero contenido. En ese sentido, el análisis de los conceptos interpretativos es sustantivo, normativo y comprometido. ${ }^{11}$

El derecho es completamente moral, así como la teoría del derecho y las leyes particulares; el derecho es una rama de la política que es una rama de la moralidad, en ese sentido, ningún hecho

${ }^{8}$ Dworkin, Ronald, "Hart's Postcript and the Character of Political Philosophy", Oxford Fournal of Legal Studies, Vol. 24, No. 1, 2004, pp. 9, 13.

${ }^{9}$ Ibidem., p. 15.

10 Vega Gómez, Juan, "La postura metodológica de Dworkin: lo interesante de la crítica", Ensayos de filosofia jurídica analítica, Madrid, Dykinson, Instituto de Investigaciones Jurídicas-UNAM, 2014, p. 45; Dworkin, "Hart's Postcript and the Character of Political Philosophy", p. 9.

${ }^{11}$ Ibidem., p. 3. 
social determina el derecho, sólo los valores pueden hacerlo. ${ }^{12}$

A diferencia de otros planteamientos teóricos, para el interpretativismo no existe una línea divisoria entre la teoría del derecho y la administración de justicia o cualquier otro aspecto de la práctica jurídica. Desde esta perspectiva, la labor de los filósofos consiste en debatir el fundamento interpretativo como la parte general de cualquier argumento jurídico, mientras que cualquier argumento jurídico práctico asume algún tipo de fundamento abstracto que ofrece la filosofía del derecho. En ese sentido, "la opinión de un juez es en sí misma una pieza de filosofía del derecho... La filosofía del derecho es la parte general de la administración de justicia, el prólogo silencioso de cualquier decisión jurídica." ${ }^{13}$

Desde esta perspectiva, el argumento jurídico es un argumento moral. Al tener el derecho este carácter, debemos tratar de abordar los problemas jurídicos de esta manera: asumir que la forma adecuada de entender esos conceptos valiosos es a la luz de otros valores morales, de sus conexiones y relaciones mutuas, a través de una red de convicción que brinda apoyo mutuo entre valores. ${ }^{14}$

En ese sentido, Dworkin considera que lo valioso del derecho es la legalidad o estado de derecho. Así, la explicación del concepto de derecho debe capturar el valor de la legalidad y explicarlo desde su mejor perspectiva, de tal forma que podamos saber lo que la legalidad requiere en un sistema jurídico concreto y en un caso concreto, atendiendo a las prácticas institucionales y a la historia de esa jurisdicción. Ése es el trabajo de los filósofos del derecho (en el plano abstracto) y de jueces y abogados (en el plano práctico). ${ }^{15}$

Si lo valioso del derecho es la legalidad y lo valioso de la legalidad es que establece límites y requisitos para el ejercicio del poder por

${ }^{12}$ Guest, op. cit., p. 58.

${ }^{13}$ Dworkin, Law's Empire, cit., p. 90.

${ }^{14}$ Dworkin, "Hart's Postcript and the Character of Political Philosophy", pp. 4, 17,23 .

${ }^{15}$ Ibidem., pp. 24, 35. 
parte del Estado, entonces la explicación del concepto de derecho debe partir de una noción que justifique la coerción del Estado e interpretar las relaciones mutuas de este concepto normativo con otros conceptos normativos para después considerar el material jurídico, de tal forma que genere una interpretación que muestre el derecho desde su mejor perspectiva. ${ }^{16}$

Así cabe preguntarnos concretamente ¿cuál es el valor o propósito del precedente? De los diferentes pasajes de los textos de Dworkin se desprende que la integridad, la justicia y la equidad son principios que tienen un papel central en la administración de justicia y la toma de decisiones judiciales; no obstante, parece ser que lo valioso del precedente es la integridad, debido a que es el valor decisivo para los jueces acerca de lo que deben reconocer como derecho.

En ese sentido, la teoría del precedente debe poder explicar el aspecto normativo del mismo, es decir, debe poder explicar la integridad como lo valioso del precedente y la manera de hacerlo es a través de la interpretación constructiva que muestre la interrelación de la integridad con la justicia y la equidad.

Recordemos que la integridad se acepta como un ideal político, porque en este enfoque se quiere tratar a la comunidad política como una comunidad de principio, es decir, como una comunidad que comparte los mejores principios comunes que se puedan encontrar. No obstante, la integridad es distinta de la equidad y la justicia, pues éstas últimas se persiguen a través de la integridad. ${ }^{17}$

Se asume entonces que la comunidad como entidad puede comprometerse con los principios de equidad, justicia o el debido proceso de manera semejante a como lo haría una persona común; esta idea identifica a la comunidad como una entidad distinta de las personas que la componen, capaz de tener voluntad moral y

\footnotetext{
${ }^{16}$ Vega, op. cit., p. 46.

${ }^{17}$ Dworkin, Law's Empire, cit., p. 263.
} 
responsabilidad. ${ }^{18}$ En general se asume que la propia comunidad tiene ciertas obligaciones de imparcialidad hacia sus miembros y que los funcionarios actúan como agentes de esa comunidad, de modo que esa responsabilidad es previa a aquella de los funcionarios quienes actúan a nombre de la comunidad. ${ }^{19}$

Una comunidad de principio acepta que sus derechos y obligaciones no se agotan en las decisiones políticas tomadas por las instituciones, sino que dependen más bien del esquema de principios que esas decisiones presuponen y respaldan. Cada miembro, por consiguiente, tiene derechos y obligaciones que surgen de ese esquema, aun cuando no hayan sido nunca formalmente identificados o declarados. ${ }^{20}$

\section{LA INTERPRETACIÓN CONSTRUCTIVA}

La interpretación es una herramienta esencial para explicar los conceptos interpretativos. Al igual que otros teóricos, Dworkin distingue la interpretación que se puede llevar a cabo en distintas esferas y contextos, por ejemplo, la interpretación de una conversación, la interpretación artística de pinturas u obras literarias. Interpretamos cuando escuchamos a otras personas hablar para decidir qué es lo que se dijo; se interpretan poemas o pinturas para defender su significado, punto o tema. Desde este enfoque se considera a la interpretación artística es semejante a la interpretación de prácticas sociales en el sentido de que ambas son creativas y están asociadas directamente a propósitos. ${ }^{21}$

La "interpretación constructiva” consiste en imponer propósito o valor a un objeto o práctica para hacer de ésta el mejor ejemplo posible

\footnotetext{
${ }^{18}$ Ibidem., p. 168.

${ }^{19}$ Ibidem., p. 175.

${ }^{20}$ Ibidem., p. 211.

${ }^{21}$ Ibidem, pp. 50-51.
} 
del género al que pertenece. ${ }^{22}$ Esto significa que la interpretación de las prácticas sociales (y obras de arte) es constructiva en el sentido de que los propósitos a los que atiende son fundamentalmente aquellos propósitos impuestos por el intérprete, no por el autor de la práctica u objeto.

En ese sentido, la interpretación es una labor de asignación de valor o propósito, pero eso no significa que en la interpretación constructiva el intérprete pueda asignar cualquier propósito al objeto o práctica, ya que la historia o forma de la práctica restringen las posibles interpretaciones a las que se puede recurrir; la interacción entre propósito y objeto de interpretación está delimitada según el tipo de metas, principios o intereses a los que la práctica ha servido. Esto no significa que todas las prácticas sean moralmente buenas, simplemente que debemos verlas a la luz de los mejores argumentos posibles para dicha práctica. ${ }^{23}$

Así, una interpretación constructiva se lleva a cabo en tres etapas: la etapa pre-interpretativa, la etapa interpretativa y la etapa posinterpretativa, cada una de las cuales requiere de distintos grados de consenso dentro de la comunidad. ${ }^{24}$

En la etapa pre-interpretativa se identifican las reglas y estándares vigentes que proporcionan el contenido tentativo de la práctica. En la etapa interpretativa el intérprete establece una justificación general para los principales elementos de la práctica identificados en la etapa previa: por qué es valiosa la práctica tal como es, si bien no requieren cubrirse todos los aspectos de la práctica si debe ser adecuada para mostrar que se trata de esa práctica y no de una nueva. La etapa pos-interpretativa es la etapa final, se conoce como etapa de reforma en la que el intérprete decide lo que la práctica realmente "requiere" para servir mejor a su justificación, en esta

\footnotetext{
${ }^{22}$ Ibidem., p. 52.

${ }^{23}$ Guest, op. cit., p. 68.

${ }^{24}$ Dworkin, Law's Empire, cit., pp. 52, 65.
} 
etapa es cuando se puede asignar un nuevo valor que justifique mejor la práctica. ${ }^{25}$

De esta forma la interpretación constructiva da cuenta de que todas las prácticas sociales cambian y van adquiriendo nuevas formas, de modo que el contenido que tiene hoy cierta práctica puede ser distinto mañana. Este hecho está directamente vinculado a la "actitud interpretativa" de la comunidad, la cual consta de dos elementos constitutivos: El primero, es la asunción de que la práctica además de existir tiene un valor, sirve a algún propósito o refuerza algún principio. El segundo, es la asunción de que los requerimientos de la práctica no son necesaria ni exclusivamente los que se asumían, sino que son sensibles al propósito de la práctica para entenderla, aplicarla, extenderla, modificarla o limitarla según ese propósito. De esta forma, las personas imponen significado a la institución o práctica para verla desde su mejor perspectiva y reestructurarla a la luz de ese significado. ${ }^{26}$

Conforme la actitud interpretativa se va desarrollando se vuelve crítica y va demandando incluir nuevas acciones dentro de la práctica o excluir algunas previamente reconocidas que sirvan mejor al valor de esa práctica. La interpretación entonces se aplica sobre la práctica, cambiando su forma, la cual está sujeta a constante reinterpretación según lo requiera la práctica. Como he señalado, desde esta perspectiva, conceptos como derecho, precedente, justicia o cortesía son conceptos interpretativos, susceptibles de abordarse con la actitud interpretativa y las tres etapas de la interpretación. ${ }^{27}$

${ }^{25}$ Flores, Imer B., "The Legacy of Ronald Dworkin (1931-2013): A Legal Theory and Methodology for Hedgehogs, Hercules and One Right Answers", consultado el 20 de octubre de 2020 en http://scholarship.law.georgetown.edu/facpub/1454, p. 19; Dworkin, Law's Empire, cit., pp. 65-66.

${ }^{26}$ Flores, "The Legacy of Ronald Dworkin...", cit., pp. 18-19; Law's Empire, cit., p. 47.

${ }^{27}$ Ibidem., pp. 48, 73. 
Esto se ilustra más claramente con los ciudadanos de la cortesía, quienes en el pasado consideraron que el valor de la práctica de la cortesía era el respeto, el cual requería a los hombres acciones como quitarse el sombrero ante la nobleza. La actitud interpretativa muestra como primer elemento constitutivo que la práctica de la cortesía sirve a un propósito: mostrar respeto, pero al mismo tiempo muestra el segundo elemento constitutivo, ya que la actitud interpretativa es sensible a los requerimientos y propósitos de la cortesía, por lo que en una época posterior la práctica puede cambiar y así los ciudadanos pueden considerar que la cortesía ya no requiere las acciones pasadas sino que ahora requiere que los hombres se quiten el sombrero ante las mujeres, por ejemplo, modificando las acciones que sirven mejor a su propósito: el respeto. ${ }^{28}$

Es preciso notar que para realizar la labor de identificar el contenido tentativo de la práctica (etapa pre-interpretativa) se requiere que los miembros de la comunidad interpretativa compartan - incluso ampliamente - las mismas asunciones acerca de lo que cuenta como parte de la práctica, así como qué tanto ha de ajustarse la justificación propuesta en la etapa interpretativa para ser aceptada como una interpretación de la propia práctica. ${ }^{29}$

De este modo, aunque los miembros de la comunidad comparten un sentido pre-interpretativo de la práctica, éste es aproximado porque según indica Dworkin, la interpretación es necesaria aun en esta etapa inicial debido a que las reglas sociales no tienen etiquetas de identificación, ${ }^{30}$ por tanto, los límites de la práctica no son seguros o precisos ni siquiera en esta etapa, ${ }^{31}$ lo más relevante

${ }^{28}$ Ibidem., p. 47.

${ }^{29}$ Ibidem., p. 67.

${ }^{30} \mathrm{Al}$ parecer por interpretación en este pasaje se refiere únicamente a la distinciónidentificación de la práctica a interpretar. Ibidem., p. 66.

${ }^{31}$ Ibidem., pp. 75, 425; En la nota al pie 22 se señala que, dado que la etapa preinterpretativa requiere interpretación, dichos límites alrededor de la práctica no son precisos ni seguros. 
en este punto es que la comunidad comparta de manera general qué es lo que cuenta como parte de la práctica. ${ }^{32}$

En este orden de ideas encuentran sentido los paradigmas dentro del proceso de interpretación ya que son relevantes para el razonamiento jurídico al afianzar ciertas interpretaciones de manera temporal y aunque prevalecen por algún tiempo, ningún paradigma está exento de ser desafiado por una nueva interpretación que establezca un nuevo y diverso paradigma que relegue el anterior como una equivocación. Los paradigmas hacen posible una forma estandarizada de argumento de manera provisional. ${ }^{33}$

No obstante, de manera particular, quienes adoptan una actitud interpretativa consideran - no que su interpretación es distinta, sino - que su interpretación es objetivamente mejor que otras interpretaciones. ${ }^{34}$ Aunque se acepta que las convicciones de los propios jueces pueden diferir, esta divergencia se mitiga al asegurar que hay varias fuerzas que promueven la convergencia.

Una de las influencias más poderosas a favor de la convergencia es el precedente, que al no poder ser ignorado por los jueces impulsa el acuerdo; el ambiente intelectual y el lenguaje común son otros aspectos que ejercen limitaciones prácticas a la idiosincrasia, así como limitaciones conceptuales a la imaginación; finalmente la educación jurídica es otra de las influencias que promueve la convergencia, así como los procesos de selección de jueces. ${ }^{35}$ Ahora bien, esta concepción del derecho insiste en que, al ser juicios interpretativos, las afirmaciones jurídicas combinan elementos de visión hacia el pasado y visión hacia el futuro, de modo que

${ }^{32} \mathrm{Al}$ respecto, Stephen Guest señala que el planteamiento de Hart sobre el derecho como la unión de reglas primarias y secundarias puede ser entendido como una actitud pre-interpretativa en el sentido de que intenta describir un consenso en torno al derecho. Guest, op. cit., p. 71.

${ }^{33}$ Dworkin, Law's Empire, cit., pp. 72, 89, 92.

${ }^{34}$ Ibidem., p. 76.

${ }^{35}$ Ibidem., p. 88. 
la práctica jurídica se interpreta vista como una narrativa política desdoblada. ${ }^{36}$

A pesar del atractivo en torno a la interpretación constructiva, existe un desafío latente relacionado con la identificación del precedente judicial. Si suponemos que la interpretación constructiva es una actividad permanente, entonces, no existe distinción alguna entre un precedente judicial y cualquier otra resolución judicial. Esta afirmación parece contraintuitiva porque de alguna manera creemos que los precedentes tienen alguna importancia para la práctica judicial y asumimos que no todo el universo de resoluciones judiciales existentes tiene el alcance y la fuerza para contar como precedentes.

Entonces ¿cómo es posible que identifiquemos como "especiales" a las resoluciones judiciales que son precedentes, pero las tratemos como cualquier resolución? Esta contradicción ocurre al decidir la fuerza que se le asigna y eso es precisamente lo que parece indicar este enfoque teórico. ¿Qué es entonces aquello que distingue y diferencia a un precedente del resto de resoluciones judiciales? Los teóricos parecen coincidir en que aquello que forma precedente es la parte que aporta las razones para la decisión u obiter dicta, y si bien no hay uniformidad acerca de su caracterización, es comúnmente aceptado que no toda sentencia judicial tiene este carácter. ${ }^{37}$ Parece entonces, necesaria alguna distinción adicional que permita esta diferenciación en el marco de la interpretación constructiva.

Si consideramos que la guía que aporta el precedente está en los principios, podemos preguntarnos ¿cómo podemos identificar qué decisiones judiciales cuentan como precedentes? Si bien

\section{${ }^{36}$ Ibidem., p. 225.}

37 Gascón Abellán, Marina, "Motivación de las sentencias y jurisprudencia. ¿Cumple nuestra jurisprudencia su función?”, en Álvaro Núñez Vaquero y Marina Gascón Abellán (coords.) La construcción del precedente en el Civil Law, Barcelona, Atelier Libros Jurídicos, 2020, p. 167; Sodero, Eduardo, "Sobre el cambio de los precedentes", DOXA. Cuadernos de Filosofia del Derecho 39 (2016), p. 239. 
los precedentes no clausuran el diálogo de manera definitiva, ${ }^{38}$ resultaría difícil reconocer que los tribunales realmente se guían por precedentes si no hay forma suficientemente clara para identificarlos como sugiere la teoría interpretativista.

$\mathrm{Al}$ respecto, aporta luz la distinción de Hart sobre la necesidad de conciliar dos necesidades básicas al interior de los sistemas jurídicos: proporcionar reglas claras que se puedan aplicar de manera directa, y reglas abiertas que se especifiquen al momento de su aplicación. ${ }^{39}$ Todo sistema jurídico opera con ciertas reglas estables cuya aplicación no es controvertida, por lo que la posibilidad de un ejercicio interpretativo permanente desafía un rasgo característico de la práctica judicial.

Podríamos pensar que la respuesta está en la idea de que sólo aquellos casos que se resuelven por principios tienen la fuerza para abarcar casos futuros pero ello no proporciona una guía suficiente porque se trata de un criterio para la toma de decisiones judiciales en general y no solo para las que tienen carácter de precedente en particular, por lo que muchas decisiones judiciales pueden ser decididas por principios sin ser precedentes y aun cuando las decisiones judiciales sean decididas por principios pueden estar sujetas a los desacuerdos.

El problema de identificación del precedente en la teoría interpretativista de Dworkin es relevante en la medida en que la falta de identificación del material jurídico que constituye la historia institucional afecta profundamente el llamado "acuerdo inicial" de la etapa pre-interpretativa, por lo que conviene tener presente los efectos y alcances que las objeciones pueden tener en la explicación general.

${ }^{38}$ Ibid., p. 231.

${ }^{39}$ Hart, H. L. A., El concepto de derecho, $2^{\text {a }}$ ed., trad. de Genaro R. Carrió, Buenos Aires, Abeledo-Perrot, 1995, pp. 162-163. 


\section{LOS PRINCIPIOS EN EL RAZONAMIENTO JUDICIAL}

Llevar a cabo la interpretación constructiva es una labor sumamente compleja que no sería posible en un esquema que admita solo hechos sociales como fuentes del derecho. Es por ello que - en el derecho como interpretación - el material jurídico no se agota con las reglas jurídicas, sino que hay otros estándares que son parte del derecho, esto es, políticas y principios. Una política es un estándar que establece una meta a alcanzar para lograr alguna mejora económica, política o social en la comunidad. Por otra parte, los principios son estándares que se aplican por su requerimiento de justicia, equidad o alguna otra dimensión de la moralidad. ${ }^{40}$

$\mathrm{Al}$ respecto Dworkin explica que un gran número de casos judiciales son resueltos tomando como sustento principal, no las normas jurídicas sino este otro tipo de estándares. El ejemplo que tradicionalmente revela el papel central de los principios en el derecho es el caso Riggs vs. Palmer en el que se discute acerca de si un nieto (Elmer E. Palmer) que asesinó a su abuelo (Francis B. Palmer) puede heredarle, situación no determinada por el derecho de sucesiones del estado de Nueva York. En el caso, los argumentos vertidos para negar la herencia a Elmer se basaron en el principio general del Common Law de que "A nadie se le debe permitir beneficiarse de su propio fraude, o tomar ventaja de su propio error, fundar cualquier demanda sobre su propia iniquidad, o adquirir propiedad sobre la base de su propio crimen". ${ }^{41}$

Este caso muy particularmente muestra el papel de los principios en el razonamiento judicial, materializado por el juez Earl, quien señaló la necesidad de construir las normas jurídicas desde los

${ }^{40}$ Dworkin, Taking Rights Seriously, Cambridge, Massachusetts, Harvard University Press, 1977, p. 22.

${ }^{41}$ Jiménez Cano, Roberto M., Fabra Zamora, Jorge Luis y Guzmán Buelvas, Carolina Esther, "Riggs contra Palmer. Tribunal de Apelaciones de Nueva York - 115 NY 506", Revista Telemática de Filosofia del Derecho, núm. 11, 2007/2008, p. 363. 
textos, no en aislamiento histórico sino a la luz de los principios, lo cual significa que los jueces deben construir la norma jurídica para adecuarla tanto como sea posible a los principios de justicia asumidos en el derecho y hacer al sistema coherente en principio. ${ }^{42}$

Los principios inclinan la decisión en una dirección particular, sin embargo - opina Dworkin - el empleo de principios morales no significa que los jueces tengan discreción, porque los principios pueden dictar un resultado. Cualquiera que sea el resultado, es un resultado que proporcionó el principio y no uno que generó el juez libremente. El juez que decide mediante un principio está en la misma posición del soldado que tiene la obligación de elegir a los subordinados más experimentados, en el sentido de que ninguno tiene discreción, porque ambos tienen el deber de alcanzar una comprensión (controvertida o no) de lo que el principio o la experiencia requieren y actuar de acuerdo con ello. ${ }^{43}$

Como se advierte, la aportación y distinción de los principios en el razonamiento judicial es de gran importancia. Los tribunales emplean principios cuando resuelven asuntos, aunque incluso los principios requieren interpretación para obtener los beneficios de su aplicación al caso concreto. El solo hecho de citar un principio no resuelve el asunto porque los principios no dictan un resultado específico, solo conducen en una dirección.

\section{LA TAREA JUDICIAL EN EL DERECHO COMO INTEGRIDAD}

El esquema de los elementos implícitos en la concepción del precedente estaría incompleto si no se examina el papel de los principios en el razonamiento judicial, así como de este último en el derecho como integridad. El planteamiento nos conduce a la pregunta indispensable: ¿Qué es la integridad? La integridad puede entenderse como un principio de actuación moral correcta, demandamos

\footnotetext{
${ }^{42}$ Dworkin, Law's Empire, cit., pp. 19-20.

${ }^{43}$ Dworkin, Taking Rights Seriously, cit., pp. 35-36.
} 
integridad porque independientemente de las diferencias de opinión entre nosotros, las demandas de moralidad son coherentes a tal grado que eliminan los comportamientos caprichosos. Cuando actuamos moralmente, actuamos con integridad. ${ }^{44}$

La falta de integridad implica una falta de compromiso con un comportamiento moral, por esto es por lo que valoramos el actuar íntegro porque indistintamente refleja un compromiso con una visión moral coherente y defendible. Esto es así porque las demandas de moralidad son coherentes en sí mismas, por lo cual la integridad está asociada indistintamente a la moral. ${ }^{45}$

La integridad en el derecho puede entenderse como un ideal y como una demanda que exige que éste se cree o interprete siempre de manera que forme una unidad integral. ${ }^{46}$ Según Dworkin, la integridad en el derecho tiene dos principios uno legislativo y uno de administración de justicia. El primero instruye a los legisladores a intentar hacer el conjunto total de leyes moralmente coherente, el segundo instruye a los jueces a ver al derecho como portador de un conjunto moralmente coherente de principios tanto como sea posible e interpretar con la idea de encontrar estándares implícitos entre y más allá de los estándares explícitos. ${ }^{47}$

Es posible, sin embargo, que se ignore la integridad cada vez que se aprueban leyes coherentes en sí mismas pero que no se ajustan al universo de principios de justicia y equidad en su conjunto, de hecho, continuamente se viola la integridad de esta manera, pero, aunque no se pueda reunir a todas las normas jurídicas bajo un esquema de principio coherente, la integridad debe aceptarse como un ideal político. ${ }^{48}$

${ }^{44}$ Hershovitz, Scott (ed.), "Integrity and Stare Decisis", Exploring Law's Empire. The Jurisprudence of Ronald Dworkin, 2008, p. 114.

${ }^{45}$ Idem.

${ }^{46}$ Guest, op. cit., p. 78.

${ }^{47}$ Dworkin, Law's Empire, cit., pp. 176, 217.

${ }^{48}$ Ibidem., p. 184. 
En el caso concreto del precedente, la integridad es de gran importancia ya que implica reconocer que la actuación pasada es relevante para las decisiones que los jueces toman en el presente, la integridad les requiere mantener un compromiso con una visión moral concreta, la cual solo puede mostrarse a través de un patrón de comportamiento a lo largo del tiempo; los cambios constantes demuestran capricho y no integridad. ${ }^{49}$

Particularmente, Scott Hershovitz explica con profunda claridad que los tribunales son agentes morales capaces de desplegar integridad tanto como las personas físicas y señala que "un tribunal muestra integridad cuando sus decisiones reflejan un compromiso con una visión coherente y defendible acerca de los derechos y obligaciones que las personas tienen bajo el derecho. Tal compromiso solo puede mostrarse a través de un patrón de decisiones a lo largo del tiempo." 50

Aceptar el derecho como integridad parece ofrecer ciertas ventajas en un plano más práctico, una de ellas es la ventaja de convertirse en una forma especial de comunidad que promueve su autoridad moral para ejercer el monopolio de la coerción. La integridad brinda protección contra la parcialidad, el engaño o cualquier otra forma de corrupción. Contribuye a la eficiencia del derecho porque cuando las personas aceptan que están gobernados no solamente por normas explícitas sino también por otros estándares que se derivan de los principios implícitos en otras decisiones, entonces las personas podrán ir advirtiendo gradualmente qué principios se requieren en las nuevas circunstancias sin necesidad de una legislación detallada sobre cada punto de conflicto. Finalmente, la integridad sirve como un vehículo para el cambio orgánico aun cuando no es completamente efectivo. ${ }^{51}$

\footnotetext{
${ }^{49}$ Hershovitz, op. cit., p. 114.

${ }^{50}$ Ibidem., p. 115.

${ }^{51}$ Dworkin, Law's Empire, cit., pp. 188-189.
} 
Ahora bien, Dworkin señala que los jueces desempeñan una labor distinta a la de los legisladores, en tanto están llamados a resolver los asuntos en términos de principio y no de política para argumentar por qué las partes tienen o no los derechos que se determinan en su sentencia. El juez puede desarrollar posibles interpretaciones aplicables al caso y contrastar cada una contra decisiones judiciales pasadas, incluso buscando más allá del tema específico que pudieran relacionarse para determinar cuál podría formar parte de una teoría coherente que justifique la totalidad de decisiones. ${ }^{52}$ Esta forma de proceder del juez se conoce como una serie de círculos concéntricos que consiste en contrastar los casos que se ajusten sobre el tema inmediato para después ir expandiendo la búsqueda gradualmente a casos cada vez más generales. Por supuesto, esta no es una tarea simple sino más bien una tarea sumamente compleja.

En buena medida, la labor de los jueces consiste en construir la "verdadera" norma jurídica a partir del texto contenido en la ley, de la misma forma en la que un crítico necesita una teoría, digamos de interpretación para reconstruir un poema desde el texto, de la misma forma los jueces necesitan hacer algo semejante con las leyes. Esta labor, no se limita a las normas jurídicas vagas o ambiguas, sino que es una labor necesaria en todos los casos, incluso si la redacción es impecable, justo como sucedió en el caso Riggs vs. Palmer en el que las palabras en la ley de sucesiones no eran vagas ni ambiguas, sino que el desacuerdo radicó en cómo construir la norma jurídica en las circunstancias especiales del caso. ${ }^{53}$

En el plano jurisdiccional, desde el derecho como integridad los jueces tienen la misión de identificar derechos y obligaciones bajo la idea de que fueron creados por un solo autor - la comunidad personificada- para expresar a través de ellos una concepción

\footnotetext{
${ }^{52}$ Ibidem., pp. 244-245, 250.

${ }^{53}$ Ibidem., p. 17.
} 
coherente de justicia y equidad. ${ }^{54}$. Los jueces deben asumir (tanto como les sea posible) que el derecho está estructurado por un conjunto de principios coherentes acerca de la justicia, la equidad y el debido proceso, los cuales habrán de aplicarse a los nuevos casos, de modo que los casos sean resueltos con los mismos estándares. ${ }^{55}$

En la toma de decisión judicial es fundamental atender a la distinción entre argumentos de política, que justifican una decisión política al mostrar que la decisión avanza o protege alguna meta colectiva de la comunidad en su conjunto, o argumentos de principio, que justifican una decisión política al mostrar que ésta asegura derechos individuales o de grupo. Dado que los argumentos de principio establecen derechos individuales, mientras que los argumentos de política son argumentos políticos que intentan establecer metas colectivas, Dworkin propone que las decisiones judiciales, particularmente en los casos difíciles se generan y deben generarse por principios, no por política. ${ }^{56}$

Esto, debido a que las políticas promueven metas que no aseguran recursos, oportunidades o libertades para individuos particulares, quienes quedan supeditados al interés de los grupos, por ejemplo, la eficiencia económica es una política que promueve el bienestar de la mayoría sin importar el individuo. En ese sentido, se entiende que un derecho no puede pesar más ni estar supeditado a una meta social, de ahí que las decisiones judiciales se sustenten en principios. ${ }^{57}$

Dado el entramado teórico hasta ahora planteado, sale a luz que la labor de los jueces, incluso en los casos difíciles es "descubrir" los derechos que tienen las partes, no inventar nuevos derechos ${ }^{58}$

${ }^{54}$ Ibidem., p. 225.

${ }^{55}$ Ibidem., p. 243.

${ }^{56}$ Dworkin, Taking Rights Seriously, cit., pp. 82, 84, 90, 97.

${ }^{57}$ Ibidem., pp. 91-92.

${ }^{58}$ Flores, "The Legacy of Ronald Dworkin...", cit., pp. 24-25; Dworkin, Taking Rights Seriously, cit., p. 81. 
aun cuando se trate de casos difíciles, pues al estar inmersos en una estructura de derechos institucionales debemos "suponer" que incluso los casos difíciles tienen una respuesta correcta, no porque las reglas sean exhaustivas y completamente claras sino como una afirmación acerca de los oficiales y sus responsabilidades. ${ }^{59}$

Esta postura tiene la idea implícita de la completitud del derecho, es decir, la idea de que toda situación está regulada y determinada en un sistema jurídico si es que existe una regla o principio en ese sistema que cualifique la acción. La afirmación de los contenidos implícitos del derecho evita la indeterminación jurídica y conduce a una "determinación ex post facto" para cualquier caso que se presente. $^{60}$

El que exista una respuesta correcta no significa que se trate de una respuesta a descubrir o que se pueda deducir sino de una respuesta que ha de ser construida desde los materiales jurídicos pre-existentes, por otra parte, tampoco significa que sea una respuesta inventada o modificada, sino una respuesta surgida de la interpretación. ${ }^{61}$ La noción de que el derecho (reglas y principios) siempre puede determinarse aun cuando se trate de un caso disputado descansa en la asunción de que cualquier problema jurídico puede resolverse con mecanismos de interpretación jurídica. ${ }^{62}$

Así, lo que hacen los jueces es prácticamente ejecutar derechos políticos pre-existentes, de esta forma la historia institucional funciona como un elemento de la decisión. En este enfoque no

${ }^{59}$ Ibidem., p. 104. Ramírez Anguiano, Diego, "Derecho, moral e interpretación: correlación entre la filosofía analítica de H. L. A. Hart, el pensamiento de Lon Fuller y Ronald Dworkin”. Problema. Anuario de Filosofia y Teoría del Derecho, núm. 13, 2019, p. 413.

${ }^{60}$ Del Real Alcalá, Juan Alberto, "The Controversies about Legal Indeterminacy and the Thesis of the 'Norm as a Framework' in Kelsen", European Fournal of Legal Studies, Vol. 6, No. 2, Autumn-Winter 2013-2014, pp. 176, 178.

${ }^{61}$ Flores, "The Legacy of Ronald Dworkin...", cit., p. 26.

${ }^{62}$ Del Real, "The Controversies about Legal Indeterminacy...”, cit., p. 179. 
existe tensión entre originalidad judicial e historia institucional porque las decisiones que tomen los jueces deben reflejar las decisiones políticas del pasado. Básicamente, las decisiones no se toman individualmente sino tomando en consideración una teoría global de principios y políticas que sean consistentes con otras decisiones. ${ }^{63}$ Las respuestas correctas surgen en el marco del pasado y de la historia institucional, que importan en la medida en que sirven al presente para justificar las decisiones políticas del pasado. ${ }^{64}$

III. EL PRECEDENTE EN EL INTERPRETATIVISMO: LOS ELEMENTOS EXPLÍ́CITOS

Los elementos revelados hasta ahora son elementos implícitos que subyacen a la explicación del concepto de precedente y con los cuales podemos conocer la correcta dimensión de la explicación. Con estos elementos implícitos en mente podemos ahora atender y analizar los elementos explícitos de la concepción del precedente de Ronald Dworkin.

\section{Sobre el carácter del precedente}

Partimos pues de la idea de que el precedente en este enfoque teórico se entiende como el reporte de una decisión política previa que ejerce una fuerza gravitacional sobre casos futuros en la medida en la que se fundamenta en principios y en los términos de la extensión de tales principios. Las decisiones políticas son todas aquellas decisiones que contribuyen a definir los contornos y contenidos del Estado como una comunidad política. Las decisiones judiciales con carácter de precedente son decisiones políticas en la medida en que ayudan establecer o modificar los contornos y contenidos que determinan la forma de ser de una comunidad política.

${ }^{63}$ Dworkin, "Hard Cases", cit., p. 1064; Dworkin, Taking Rights Seriously, cit., p. 87.

${ }^{64}$ Dworkin, Law's Empire, cit., p. 227. 
Debe tenerse en cuenta que, en este enfoque, la comunidad política es una que acepta la integridad como un ideal, es una comunidad que acepta que los derechos y obligaciones de sus miembros surgen no solo de las decisiones políticas tomadas en el pasado y que tienen forma de leyes o reglamentos sino que los derechos y obligaciones de sus miembros surgen también del esquema de principios que la propia comunidad ha aceptado respaldar aun cuando nunca antes hayan sido identificados o formalmente declarados. ${ }^{65}$

La distinción de algunas decisiones judiciales como decisiones políticas les otorga (en un primer momento) mayor importancia que al resto de las decisiones judiciales en tanto que considera la posibilidad de recurrir a ellas, pero la propia caracterización del precedente parece no ofrecer una forma clara de identificar los precedentes en el marco de la propia teoría, ya que, en buena medida toda decisión judicial puede caracterizarse como una decisión política.

A diferencia del planteamiento en la teoría hartiana en torno a las decisiones judiciales, por ejemplo, el interpretativismo no distingue entre casos centrales y casos periféricos en la práctica jurídica, sino que sitúa el universo de casos posibles en la categoría de los pivotal cases como cualquier caso cuya respuesta real o posible se encuentra explícita o implícitamente en el derecho. La diferencia en esta teoría entre casos fáciles y casos difíciles radica en los diferentes grados de complejidad que implica cada caso dentro de la misma tipología. ${ }^{66}$

En ese sentido, la solución de los casos fáciles como pivotal case entraña menor dificultad debido a que su respuesta correcta se encuentra explícita en el derecho y puede identificarse sin mayor problema; por otro lado, los casos difíciles son más problemáticos y entrañan mayor dificultad como pivotal cases porque la respuesta

${ }^{65}$ Ibidem. p. 211.

${ }^{66}$ Del Real Alcalá, Juan Alberto, "La decisión judicial según los tipos de casos: clear cases, borderline cases y pivotal cases", Problema. Anuario de Filosofia y Teoría del Derecho, núm. 1, 2007, pp. 394-395. 
correcta se encuentra implícita en el derecho y resulta más complejo identificarla. ${ }^{67}$

Dworkin ha señalado que no hay uniformidad en la forma real del precedente aun dentro de Estados Unidos o Gran Bretaña, tanto que difiere incluso de estado a estado en un mismo país, pero principalmente es posible que existan desacuerdos acerca de los detalles y aplicación de la doctrina del precedente en cuanto a qué tribunales están sujetos a las decisiones de la Suprema Corte, ${ }^{68}$ qué decisiones tienen más peso: si las recientes o las antiguas, las de los jueces famosos o las de los cualquier otro juez. En ese sentido, las opiniones de abogados al respecto pueden variar ampliamente. ${ }^{69}$

Parece que las diferencias de opinión pueden ser tan profundas que en los casos concretos pueden conducir a los jueces a discrepar acerca de si están obligados o no a seguir un determinado precedente en la cuestión a resolver. Esto sucedió en el caso McLoughlin, en el que la actora demandó daños emocionales causados por ver a su familia grave en el hospital; hasta ese momento los precedentes autorizaban compensación por daño emocional a víctimas que habían estado en la escena del accidente mientras que la señora McLoughlin había sufrido el shock dos horas después en un lugar distinto. $^{70}$

${ }^{67}$ Ibidem., p. 395.

$68 \mathrm{Al}$ respecto, Kenneth Himma difiere en torno a los desacuerdos teóricos y considera que la opinión de Dworkin acerca de lo que cuenta como derecho es inconsistente con el núcleo de la práctica jurídica en Estados Unidos ya que los oficiales consideran, a manera de práctica estandarizada, los razonamientos judiciales que resultan en nuevas reglas como jurídicamente vinculantes. Además, jueces y abogados consideran y tratan las leyes declaradas constitucionales como derecho sin importar si son consistentes con las normas morales que las mostraría desde su mejor perspectiva moral. Himma, Kenneth, “Trouble in Law's Empire: Rethinking Dworkin's Third Theory of Law", Autumn, 2003, Vol. 23 No. 3, Oxford Journal of Legal Studies, pp. 354-355.

${ }^{69}$ Dworkin, Law's Empire, cit., p. 25.

${ }^{70}$ Ibidem., pp. 26-27. 
El caso demuestra que los diferentes tribunales que revisaron el caso sostuvieron opiniones diversas al respecto, pero el problema se alega - es planteado en términos de desacuerdo acerca de cuál es el derecho en el caso concreto, sobre la fuerza y carácter del precedente en ese caso como fuente del derecho, no acerca de lo que debía hacerse ante la ausencia de derecho. ${ }^{71}$

La agrupación de los casos fáciles y casos difíciles en la categoría de pivotal cases permite afirmar que existe un patrón de resolución ideal en la administración de justicia, esto es, que empleando el procedimiento de interpretación constructiva y sus etapas todo caso puede ser solventado por el derecho. ${ }^{72}$ No obstante, la advertencia previa en la teoría interpretativa en torno a los desacuerdos en los detalles y la aplicación de la doctrina del precedente nos conduce a la pregunta acerca de ¿cuál es realmente el carácter del precedente desde esta teoría?

Las características del precedente parecen indicar que, en el enfoque del derecho como integridad, el precedente no es una regla debido a que el tratamiento que se le da permite y promueve que el contenido del precedente (digamos el principio que lo sustenta) sea reinterpretado para su aplicación al caso presente. El hecho de considerar que el precedente ha de interpretarse para su aplicación elimina automáticamente cualquier carácter excluyente, como el que suele asociarse con las reglas.

Como una observación más general, parece derivarse que en este enfoque ninguna regla tiene la cualidad excluyente, en vista de que, para la aplicación del derecho, el material jurídico que emplea el juez debe primero interpretarse, de modo que ninguna norma jurídica es realmente la que se creó mediante fuentes sociales, ya que debe pasar por las etapas interpretativas antes de estar en condiciones de aplicarse. La sola posibilidad de interpretar precedentes indica que

${ }^{71}$ Ibidem., p. 39.

${ }^{72}$ Del Real, "La decisión judicial según los tipos de casos...”, cit., pp. 402-403. 
éstos son tratados como un elemento más en el análisis o balance de razones del tribunal para arribar a la respuesta adecuada, lo cual quiere decir que - en el marco del interpretativismo- el precedente no tiene nunca un carácter concluyente para los jueces de aplicación como sus destinatarios.

Si recordamos que en la teoría interpretativista la fuerza del precedente depende de los argumentos de principio que lo sustentan, que las decisiones judiciales deben tomarse por argumentos de principio y no por argumentos de política y que el elemento que guía los casos futuros es el principio sostenido, entonces, estos elementos parecen indicar que el precedente en este enfoque es tratado en sí mismo como un principio aplicado, no como una regla. De ser así, el precedente como principio aplicado, lo que puede hacer es recomendar la dirección que ha de tomar una decisión, pero no puede proporcionar una respuesta concreta.

$\mathrm{Al}$ actuar con integridad, las personas se comprometen a actuar con un enfoque moral; una buena actuación moral sostenida en el tiempo es lo que distingue un comportamiento íntegro de uno que no lo es. En ese sentido, el derecho como integridad requiere un comportamiento moral sostenido en el tiempo, lo cual implica un compromiso con lo moralmente valioso, no un compromiso con una decisión que, aunque haya sido acertada alguna vez, resulte moralmente reprochable en el presente. La integridad no exige repetir los mismos errores. Esto significa que la integridad es compatible con la continua revisión de las creencias y los comportamientos. ${ }^{73}$

${ }^{73}$ Hershovitz, op. cit., pp. 114-115. Scott Hershovitz explica que anular y distinguir precedentes conserva el mismo compromiso con la integridad como la práctica de seguirlos, pues tanto como decir "reconocemos que nuestras decisiones previas son relevantes al decidir lo que debemos hacer ahora, pero por esas mismas razones no vamos a seguirlas ahora." Un tribunal no comprometido con la integridad tampoco sentiría la necesidad de anular o distinguir precedentes, por esto es por lo que todas estas prácticas son parte de la persecución de la integridad en la administración de justicia. Ibidem., pp. 116-117. 
En ese sentido es deseable que los tribunales actúen con integridad y el precedente promueve este tipo de integridad en la toma de decisiones judiciales. ${ }^{74}$ Este tipo de compromiso respalda la práctica del precedente flexible, ${ }^{75}$ ya que el tribunal en su compromiso con la integridad busca respetar las decisiones institucionales moralmente valiosas y atenerse a ellas, busca ser moralmente coherente consigo mismo al respetar y reproducir sus propias resoluciones, así como también es coherente al respetar y reproducir las resoluciones de otros tribunales semejantes que han resuelto antes casos semejantes en términos de integridad.

\section{LA FUERZA gRAVITACIONAL}

Los precedentes presentan la particularidad de que no están formulados de manera canónica o no contienen proposiciones específicas de la misma forma que las leyes, por esta razón, se dice, el precedente no puede ser tratado como la legislación porque ésta última, por muy vaga o general que sea, está redactada mediante formulaciones concretas, mismas que establecen los límites de las decisiones políticas. Esto conduce a una particularidad del precedente que radica en que su fuerza no está limitada por los términos lingüísticos en los que está redactada, sino que ejerce una fuerza gravitacional en decisiones posteriores aun cuando el caso posterior quede fuera de su órbita particular. ${ }^{76}$

En general, los tribunales concuerdan en que las decisiones pasadas contribuyen a la formación de nuevas decisiones y que tales

${ }^{74}$ Ibidem., p. 116.

${ }^{75}$ Recordemos que la la doctrina flexible del precedente requiere que el juez les asigne algún peso a las decisiones pasadas sobre el mismo tema; éstas incluyen tribunales del mismo nivel o tribunales en otros estados o países. Dworkin, Law’s Empire, cit., pp. 24-25.

${ }^{76}$ Dworkin, "Hard Cases", cit., p. 1087-1089; Dworkin, Taking Rights Seriously, cit., pp. 110-111. 
decisiones pasadas tienen una fuerza gravitacional sobre los casos futuros, pero no están de acuerdo - señala Dworkin - acerca de qué tanta fuerza posee tales decisiones, cómo debe interpretarse una regla o principio, si lo que se cita es realmente una regla o principio o incluso acerca de cuál es la regla o principio que estableció el precedente. ${ }^{77}$

Por ello, al definir la fuerza de un precedente particular, el juez debe tomar en cuenta los argumentos de principio que justifican ese precedente. La fuerza del precedente depende de los argumentos de principio que lo sustentan, entonces un precedente particular está justificado cuando recomienda un resultado concreto y dicho resultado debe alcanzarse en casos posteriores siempre que no se haya revocado. ${ }^{78}$

El precedente - en términos de la teoría interpretativista del derecho - no posee una fuerza propia inherente a su carácter particular, la fuerza del precedente es asignada o decidida por el juez de aplicación como se advierte en el pasaje que señala “... Hércules, cuando define la fuerza gravitacional de un precedente particular, debe tomar en cuenta solo los argumentos de principio que justifican ese precedente." 79

La teoría propone que este esquema de acción es el que opera en el razonamiento judicial, de modo que es un esquema que se aplica en la toma de decisiones judiciales de manera ordinaria y en todos los casos. Esto significa que tanto legislación como precedentes tienen siempre un carácter "provisional" en el razonamiento práctico y como tales no tienen una fuerza preestablecida, sino que están sujetos a interpretación permanentemente. De ahí que el juez de aplicación sea quien defina la fuerza gravitacional del precedente

${ }^{77}$ Ibidem., p. 112.

${ }^{78}$ Dworkin, "Hard Cases", cit., pp. 1092-1093; Dworkin, Taking Rights Seriously, cit., p. 115.

${ }^{79}$ Idem. 
que desea aplicar. ${ }^{80}$

El planteamiento, sin embargo, responde a una razón de fondo interesante: no justificar un principio que requiera a los tribunales cometer los mismos errores una y otra vez, lo cual no tiene sentido ya que incluso en circunstancias ordinarias las personas buscamos enmendar nuestros errores y no repetirlos. ${ }^{81}$ Recordemos que lo valioso de seguir precedentes es que éstos hayan sido resueltos por principios morales, ${ }^{82}$ que serán los que sustenten en el caso presente la resolución judicial.

La virtud de atender a los principios que sustentan el precedente es la posibilidad de extenderlos a otros asuntos y que puedan cubrir un amplio espectro de casos. Esta posibilidad se ve favorecida con la actitud interpretativa porque recordemos que cada caso a resolver requiere el ejercicio interpretativo del tribunal de aplicación, de esta manera, los principios contenidos en el precedente serán reinterpretados ${ }^{83} \mathrm{y}$ ajustados a la aplicación presente.

Esta forma de proceder está directamente relacionada con la integridad y la coherencia. El precedente es el instrumento que promueve la integridad, se puede decir que es la justificación o propósito al que sirve. La actuación de los tribunales de conducirse y resolver con base en principios morales en los casos presentes es resultado del compromiso de integridad que mantienen porque toman en cuenta los principios morales que otros tribunales o ellos mismos han sostenido previamente y saben que ese compromiso redundará también en los casos futuros.

${ }^{80}$ David Pannick ofrece una crítica al papel del precedente en el derecho como integridad y la fuerza gravitacional al señalar que los tribunales deben considerar los precedentes, no porque contengan la decisión correcta, sino a pesar de que pueda ser legalmente incorrecta. Pannick, David, "A Note on Dworkin and Precedent", Modern Law Review, Vol. 43, No. 1, January 1980, pp. 37-38.

${ }^{81}$ Hershovitz, op. cit., p. 103.

${ }^{82}$ Dworkin, Taking Rights Seriously, cit., pp. 84, 90, 97.

${ }^{83}$ Véase Duxbury, Neil, The Nature and Authority of Precedent, New York, Cambridge University Press, 2008, pp. 59-60. 
Cuando los tribunales recurren a un precedente, confían en los principios que fundamentan la decisión en el precedente, de esta forma se favorece la coherencia moral del derecho al resolver de forma correcta con base en principios que han probado ser correctos en el pasado. Al acudir al precedente se refuerza una justificación concreta con base en principios, y la sentencia de hoy es coherente con el derecho y la historia institucional, pues recordemos que el derecho no es un departamento separado de la moral.

El precedente permite materializar el ideal de la integridad al mostrar los derechos y obligaciones de los ciudadanos como el producto de un solo autor, permite expresar una concepción coherente de justicia y equidad $^{84}$ siempre que se aplican los mismos estándares a los casos nuevos. Actuar con integridad implica reconocer que lo que uno ha hecho en el pasado es relevante para lo que uno debe hacer en el presente. ${ }^{85}$

La labor del juez consiste no sólo en descubrir los principios que se ajusten al precedente particular que se invoca sino aquellos que se ajusten a todas las demás decisiones judiciales dentro de su jurisdicción, así como a la legislación. Ese esquema de principios proporciona una justificación coherente para todos los precedentes. ${ }^{86}$ La historia institucional juega un papel central en la explicación del precedente. ${ }^{87}$

Es importante notar que los argumentos de decisiones previas en los que se basa el juez para tomar su decisión tienen un peso inicial en su esquema de justificación cuyo objeto es satisfacer la

${ }^{84}$ Dworkin, Law's Empire, cit., p. 225.

${ }^{85}$ Hershovitz, op. cit., p. 114.

${ }^{86}$ Dworkin, "Hard Cases", cit., pp. 1093-1094; Dworkin, Taking Rights Seriously, cit., p. 116.

${ }^{87}$ Ibidem., p. 89. Stavropoulos, Nicos, "Legal Interpretivism", The Stanford Encyclopedia of Philosophy (Summer 2014 Edition), Edward N. Zalta (ed.), URL = <https://plato. stanford.edu/archives/sum2014/entries/law-interpretivist/>. Consultado el 5 de junio de 2020 . 
noción de que el gobierno debe otorgar a todas las personas los derechos reconocidos para algunos. Tal argumento de equidad que implica tratar casos semejantes de la misma manera tiene fuerza en su aplicación futura y no hacia el pasado para permitir a otros exigir derechos ya reconocidos en casos previos. La consistencia por sí misma requiere que la justificación emplee principios y razonamientos plausibles, no arbitrarios para contar realmente como una justificación. ${ }^{88}$

La posibilidad de que haya malos precedentes recuerda que el argumento de equidad que demanda consistencia en el tratamiento de casos no es el único al que los jueces deben responder pues existe la posibilidad que haya leyes o decisiones judiciales altamente rechazadas y por tanto vulnerables. Cuando este sea el caso y el juez considere que la ley o decisión es injusta, la creencia del juez es suficiente para distinguirla. ${ }^{89}$ La posibilidad de cambio, no es, sin embargo, incompatible con la integridad.

Este planteamiento general en torno al precedente revela que la consistencia en el marco del derecho como integridad implica no sólo la aplicación de la solución anunciada, sino de manera particular, la búsqueda de afinidad con el principio que sustenta el precedente en sede judicial. ${ }^{90}$ Como se aprecia, al recurrir a precedentes se busca que la solución al caso presente sea coherente con los principios morales que sustentaron la sentencia en el caso pasado.

Resulta patente pues, que la actuación judicial y la aplicación del precedente hace uso de la actitud interpretativa de manera permanente, recurre al criterio de ajuste y justificación en la búsqueda de las respuestas a los casos concretos. Parece pues, que tales criterios funcionan en dos partes, primero con el criterio de ajuste se identifica el conjunto de normas jurídicas que se ajustan

\footnotetext{
${ }^{88}$ Ibidem, pp. 118-119.

${ }^{89}$ Dworkin, "Hard Cases", cit., p. 1100; Dworkin, Taking Rights Seriously, cit., p. 122.

${ }^{90}$ Ibidem., p. 88.
} 
a la historia institucional existente para después en un segundo paso, con el criterio de justificación, asignar los principios que proporcionen una mejor justificación a esa historia institucional. La historia institucional - se observa - está compuesta por todo tipo de material jurídico como medidas legales, legislación y decisiones judiciales. ${ }^{91}$

Para aclarar cómo se interrelacionan todos estos elementos en el razonamiento judicial, Dworkin propone comparar la interpretación creativa con el crítico literario, empleando un género artificial de literatura llamado la "novela en cadena". En este género, los jueces, igual que los críticos literarios, agregan su contribución a la tradición que interpretan, lo cual será parte del material que revise el juez del futuro. ${ }^{92}$

La novela en cadena se construye por un grupo de novelistas que está encargado de escribir una novela en serie, para lo cual cada novelista tiene la tarea de interpretar el capítulo de la novela que le es entregado, a fin de escribir el siguiente capítulo que será agregado a la serie y entregado al siguiente novelista. Esta labor pretende reflejar la complejidad de resolver casos difíciles en el derecho como integridad.

Aunque se trata de diferentes novelistas, todos tienen la misión de interpretar y escribir su propio capítulo lo mejor que puedan, tomando muy en serio la continuidad de la historia, de modo que reflejen una sola novela unificada, a tal grado que la novela parezca el trabajo de un solo autor. La labor requiere adoptar un enfoque o alguna teoría acerca de los personajes, la trama, el género o el punto de la novela para decidir qué cuenta como continuación de la misma historia y qué no. ${ }^{93}$

${ }^{91}$ Solum, Lawrence B., "The Unity of Interpretation", Boston University Law Review, Vol. 90, No. 2, April 2010, pp. 553-555.

${ }^{92}$ Dworkin, Law's Empire, cit., p. 229.

${ }^{93}$ Ibidem., pp. 220-230. 
Al respecto - advierte Stephen Guest - el segundo autor y los subsecuentes autores tendrán ciertas limitaciones en torno al tipo de ajustes y la forma en la que pueden continuar la novela, aun cuando los cambios de dirección en la historia son posibles. En ese sentido, no cabría en términos de coherencia, la posibilidad de que el personaje central de la historia fuera llamado por otro nombre en el segundo capítulo, ni tampoco que la historia cambiara de trama drásticamente o que la historia cambiara de idioma dentro de la propia novela. Aunque la dimensión de ajuste de la interpretación está abierta también a interpretación, hay cierta información básica mínima que el segundo y subsecuentes autores deben satisfacer para actuar con integridad. ${ }^{94}$

Así como cada autor, cada juez del sistema jurídico deberá satisfacer las dos dimensiones en su interpretación: la dimensión de ajuste y la dimensión de justificación. En la dimensión de ajuste el juez - que emplea la actitud interpretativa - ha de asegurarse de que su interpretación fluye con los materiales jurídicos que conforman la historia institucional que le es presentada y de que su interpretación - el propósito que le asigna - tiene poder explicativo, que cubre y se ajusta a la mayor parte de los aspectos estructurales de la historia institucional.

En caso de que hubiera más de una interpretación que se ajuste al texto, tiene lugar la segunda dimensión de justificación, que le indica al juez cuál de las dos interpretaciones es la mejor. Ambas dimensiones se complementan mutuamente para llegar a la respuesta que mejor refleja la integridad del derecho. ${ }^{95}$ Debemos tener presente que el juez busca encontrar no sólo una respuesta al problema planteado sino la mejor respuesta posible.

El relato de la novela en serie tiene una gran complejidad y es valiosa en la medida en que captura la importancia del precedente

\footnotetext{
${ }^{94}$ Guest, op. cit., p. 85.

${ }^{95}$ Dworkin, Law's Empire, cit., pp. 230-231.
} 
en una dimensión temporal, lo cual logra con la asociación directa con la autoridad del derecho. La propuesta de la novela en serie explica con gran detalle los diferentes elementos que tienen lugar en la práctica del precedente, así como la forma en la que el precedente hace las veces de eslabón entre pasado y futuro de manera permanente. El precedente como promotor de la integridad funciona enlazando continuamente la historia institucional a los requerimientos presentes y señala de ese modo el curso futuro que habrán de tomar los derechos y obligaciones concretos. ${ }^{96}$

Hay, sin embargo, preguntas importantes relacionadas con la delimitación del precedente desde el interpretativismo. Si bien, no es mi propósito desarrollar a detalle estas objeciones, interesa delinearlas en el marco de la propia teoría para los debates futuros.

En el planteamiento relacionado con los principios, Dworkin advierte la posibilidad de que la integridad entre en conflicto con la justicia o la equidad. De primer momento, esto no representa un problema para la teoría misma, ya que el principio de integridad en la administración de justicia no es absoluto en relación con lo que los jueces deben hacer, solo es decisivo sobre lo que deben reconocer como derecho. El principio de integridad no tiene la última palabra sobre cómo usar el poder coercitivo del Estado sino la primera. ${ }^{97}$

No obstante, al asumir que los precedentes no tienen una forma canónica se establece que el precedente no es una regla sino un principio abierto y sujeto a interpretación, lo cual plantea nuevas preguntas que vale la pena explorar. Si entendemos que lo que

${ }^{96}$ A este fenómeno se refirió Gerald Postema cuando designó al dios romano Jano como el patrón del razonamiento jurídico con precedentes debido a la peculiar característica que posee este razonamiento de ubicarse en el umbral entre pasado y futuro y buscar integrar ambos momentos en una comprensión normativa plena. Esto, señala, ocurre en la mayoría de los sistemas jurídicos que cuentan con una buena cantidad de material jurídico constitutivo de precedentes o parecido al precedente vinculado con los casos particulares en la decisión judicial. Postema, Gerald, "Melody and Law's Mindfulness of Time", Ratio Furis, Vol. 17, No. 2, June 2004, p. 214.

${ }^{97}$ Dworkin, Law's Empire, cit., pp. 188, 218. 
establecen los jueces investidos de autoridad en los precedentes son principios (y no reglas) entonces es posible afirmar que, en cada nuevo caso, el juez de aplicación deberá interpretar y reinterpretar la resolución judicial infinitamente, lo cual indica que el precedente como material jurídico normativo no hace una diferencia en el razonamiento práctico y por lo tanto, no tiene ninguna característica especial o distintiva.

Este enfoque sugiere que los tribunales de aplicación pueden - y deben - volver a poner a balance el precedente por lo que cabe preguntar ¿qué sentido tiene entonces el precedente si es considerado como principio en sí mismo? Recordemos que los principios no proporcionan respuestas, sino orientación acerca de la dirección de una decisión. Esta forma de concebir la práctica cuestiona el papel de los precedentes en los sistemas jurídicos en virtud de que, al tratarlos como principios, se desdibuja su papel en el razonamiento judicial, pues no aportarían nada distinto a lo que aportan los principios en sí mismos. Esto es, no habría diferencia alguna entre los precedentes y el recurso al razonamiento moral (todos los elementos considerados), ${ }^{98}$ con lo cual, podríamos prescindir del primero.

Si asumimos que cada caso requiere reinterpretación permanente del precedente, entonces aceptamos que no es posible contar con material jurídico suficientemente estable para trabajar; aún más, el peso que se le asigna al precedente es el mismo peso que el de cualquier otro elemento en el razonamiento, lo cual nos lleva a cuestionar la noción misma de precedente. A la luz de teorías competitivas, el precedente estaría llamado a hacer una diferencia en el razonamiento práctico de los tribunales para lo cual debe operar como un ejemplo autoritativo. ${ }^{99}$

${ }^{98}$ Alexander y Sherwin, op. cit., pp. 134-136.

${ }^{99}$ He reflexionado sobre la calidad de ejemplaridad de los precedentes con mayor detalle en Gómora-Juárez, Sandra, "La ejemplaridad y proyección del precedente", Problema. Anuario de Filosofia y Teoría del Derecho, núm. 12, 2018. 
En otras palabras, la consecuencia que se sigue de afirmar que los precedentes son principios es que, al tratarlos de ese modo, la solución que el tribunal autoritativo estableció en el precedente no tiene la capacidad de zanjar el balance de razones para actuar en el caso particular, sino que se agrega a las demás razones que se tienen. Esta caracterización parece sugerir que el precedente no hace ninguna diferencia en el razonamiento práctico de los tribunales de aplicación (y otros sujetos a su autoridad) la cual no parece una explicación adecuada de la práctica. ${ }^{100}$

\section{Acuerdos pre-interpretativos}

La forma en que entendemos conceptos e instituciones es relevante como base de las explicaciones teóricas, incluso el interpretativismo reconoce que toma en cuenta el punto de vista interno ${ }^{101}$ de los participantes, por este motivo cabe preguntarnos ¿cuál sería el sentido de emplear el punto de vista interno si no le damos prioridad a la forma en la que los participantes se entienden a sí mismos?

De acuerdo con el interpretativismo dworkiniano, al incorporarnos a la historia de una práctica interpretativa, nuestra cultura nos presenta ciertas instituciones jurídicas como parte de un sistema, ${ }^{102}$ por ello resulta lógico pensar que el intérprete ha de comenzar su labor con la comprensión compartida y el uso que se hace de los conceptos en el momento de su incursión a la historia de la práctica interpretativa. El intérprete no se incorpora a la práctica interpretativa inventando significados a voluntad.

En ese sentido, no podemos negar que compartimos una comprensión acerca del uso de nuestros conceptos - tan general o inconsciente como se quiera - porque hacerlo implicaría negar un

${ }^{100}$ Gómora-Juárez, Sandra, El concepto de precedente, México, UNAM-Instituto de Investigaciones Jurídicas, 2018, pp. 130-131.

${ }^{101}$ Dworkin, Law's Empire, cit., pp. 14-15.

102 Ibidem., p. 91. 
presupuesto fundamental de la actitud interpretativa, esto es, que los miembros de la comunidad comparten las mismas asunciones acerca de lo que cuenta como parte de la práctica. ${ }^{103}$

La ausencia de estas asunciones compartidas haría imposible explicar las prácticas jurídicas, incluso desde el interpretativismo pues éste asume que en la etapa pre-interpretativa los miembros de la comunidad comparten una idea de qué cuenta como parte de la práctica, es decir cómo entendemos y usamos nuestros conceptos, aun cuando en etapas posteriores se entiendan de forma distinta. Negar esta posibilidad es negar la posibilidad de acuerdo en la etapa pre-interpretativa tal como se planteó que sucede, de manera que la idea de la comprensión compartida del uso de nuestros conceptos no es un elemento que podamos eliminar debido a que la teoría interpretativa del derecho depende - como otras teoríasde aceptar el punto de vista interno junto con la aceptación del uso y comprensión compartida de nuestros conceptos.

Ahora bien, debemos recordar que en el planteamiento que sugiere el derecho como integridad, la etapa pre-interpretativa - en donde tienen lugar los acuerdos pre-interpretativossólo es el punto de partida en el proceso interpretativo. Por una parte, los miembros de la comunidad comparten un sentido preinterpretativo de la práctica, aunque sea general acerca de lo que contiene y de lo que no contiene la práctica, por ejemplo para "distinguir concepciones de justicia que rechazamos, o incluso deploramos, de aquellas concepciones que ni siquiera incluiríamos como concepciones de justicia aun si se nos presentaran bajo ese título." 104 Mientras que, por otra parte, este enfoque nos indica que se requiere interpretación aun en la etapa pre-interpretativa ya que los límites de la práctica ni siquiera en esta etapa son seguros o precisos.

${ }^{103}$ Ibidem., p. 67.

104 Traducción propia, Ibidem., p. 75. 
Esto significa que los acuerdos pre-interpretativos como punto de partida se consideran solamente para poder reexaminarlos. Así, los contenidos de esos acuerdos no son seguros ni permanentes sino provisionales y cambiantes ya que con cada aplicación del material jurídico se requiere el reinicio del proceso interpretativo con sus etapas. El acuerdo pre-interpretativo en un caso concreto servirá solamente como un medio de identificación del material con el cual trabajar, que está siempre sujeto a transformaciones y adecuaciones caso a caso.

Lawrence Solum asocia directamente este elemento con la dimensión de ajuste en la interpretación al señalar que la dimensión de ajuste sirve para mostrarnos el material o aquello que va a justificarse. Esta dimensión permite trabajar con nociones y materiales existentes y no con inventos, pero esos materiales identificados tienen siempre un carácter provisional que cambiará al pasar por el proceso interpretativo que arrojará un resultado, el cual, a su vez, será tomado como el contenido del acuerdo preinterpretativo de una nueva interpretación y así sucesivamente. ${ }^{105}$

En otras palabras, en los conceptos interpretativos, el argumento está acabado por el momento (aunque no finalizado) y así también el acuerdo que puede considerarse como establecido para los propósitos de argumentos adicionales, lo cual puede confrontarse nuevamente con otras interpretaciones. ${ }^{106}$

La concepción compartida del uso de nuestros conceptos es la materia prima con la que trabaja un tribunal que sienta un nuevo precedente, ya que como un participante que construye la novela en serie, necesariamente toma en consideración el material que existe, en el cual se basa para hacer su aportación y continuar la historia; ese material jurídico contiene conceptos que usamos de una manera compartida y que entendemos de cierta forma aún antes de

\footnotetext{
${ }^{105}$ Solum, op. cit., p. 555.

${ }^{106}$ Guest, op. cit., p. 86.
} 
interpretar, el juez trabaja a partir de ellos y los transforma, por eso no es posible negar que compartimos cierto acuerdo provisional acerca del uso de nuestros conceptos.

\section{Los PARAdigmas y EL PRECEDENTE}

La reflexión previa nos conduce a examinar el papel del paradigma para el precedente. El paradigma es prueba, no de la incompatibilidad del interpretativismo jurídico hacia la comprensión compartida de los conceptos sino de un compromiso hacia el uso compartido de los conceptos, aunque con matices propios. En la comprensión tradicional, los paradigmas son, en buena medida, la materialización del uso compartido de los conceptos e implican la aceptación de significados suficientemente claros como para usarlos de manera estandarizada en el derecho. ${ }^{107}$

Es importante observar, sin embargo, que la comprensión tradicional del paradigma - usado por Hart, por ejemplo - no es la misma que emplea Dworkin en el marco de su teoría. El paradigma en la interpretación del derecho hartiana tiene sentido en relación con los casos centrales del derecho que sirven como los ejemplos centrales del concepto, cuya extensión se puede ir determinando por ciertos ejemplares que guardan semejanzas (casos periféricos) con los casos centrales o paradigmáticos. ${ }^{108}$

En esta explicación es de suma utilidad el ejemplo empleado por Hart sobre la regla que prohíbe vehículos en el parque. En este ejemplo se muestra que habría un acuerdo generalizado sobre la idea de que un automóvil es un caso central o paradigmático del concepto de vehículo, lo cual revela que compartimos, de una manera relativamente estable, el uso de ciertos conceptos.

${ }^{107}$ Dworkin, Law's Empire, cit., pp. 72, 89, 92.

${ }^{108}$ Endicott, Timothy, "Herbert Hart and the Semantic Sting", en Coleman, Jules (ed.), Hart's Postscript. Essays on the Postscript to the Concept of Law, New York, Oxford University Press, 2001, p. 42. 
No obstante, en la teoría dworkiniana el paradigma tiene una dimensión distinta. Los paradigmas cuentan como parte del material como el que se trabaja en la etapa pre-interpretativa, son parte del acuerdo que se tiene, tan es así que ninguna interpretación podría prescindir de ellos, lo cual por cierto no los hace inmunes, seguros ni los exenta del proceso interpretativo regular. En ese sentido, los paradigmas como formas tentativas de explicación son permanentemente reexaminados e interpretados.

Podemos asumir, sin embargo, que los paradigmas como parte de los acuerdos pre-interpretativos con los que se trabaja en el proceso interpretativo son fácilmente identificables a través de las fuentes sociales del derecho, aunque Dworkin ha señalado que aun en esta etapa es necesaria la interpretación, es dable pensar que la identificación del contenido tentativo de la práctica puede lograrse de manera directa sin requerir, a su vez de interpretación.

En ese sentido, la actividad en la etapa pre-interpretativa es describir el contenido de la regla en torno a la cual existe consenso. La diferencia entre la descripción y la interpretación en esta etapa radica en el nivel de aceptación o consenso de opinión. Los paradigmas para Dworkin son comprensiones estandarizadas del derecho relativamente no controvertidas, es decir que gozan de una amplia aceptación. ${ }^{109}$

Así, mientras que Hart ve en el uso de un concepto la aplicación indiscutible de un caso paradigmático, para Dworkin no existe tal conexión pues su teoría niega que las palabras por sí mismas tenga alguna aplicación independiente de la interpretación constructiva, de modo que cada cuestión de aplicación de un concepto abstracto es una cuestión interpretativa que no se conoce con anticipación. ${ }^{110}$

Ahora bien, en el marco del derecho como integridad surgen preguntas interesantes que debemos plantearnos como: ¿Cuál

${ }^{109}$ Guest, op. cit., pp. 66-67.

${ }^{110}$ Endicott, "Herbert Hart and the Semantic Sting", cit., p. 49. 
es la relación del paradigma con el precedente? y ¿cuáles son las implicaciones del paradigma para el precedente?

Como se ha explicado, los paradigmas afianzan ciertas interpretaciones de manera temporal, ${ }^{111}$ ya que los paradigmas son en sí mismos conclusiones interpretativas sobre el contenido tentativo de los conceptos, es decir, son el resultado de un proceso interpretativo previo. El paradigma como conclusión interpretativa, afianza una justificación particular por sobre otras en relación con una práctica. Cuando los tribunales recurren al precedente, confían en la conclusión interpretativa que contiene una justificación particular (paradigma) asignada a una práctica que se interpreta en sede judicial y que se ha empleado consistentemente en el pasado hasta ese momento.

Esto no significa que el juez de aplicación omite su análisis al emplear precedentes ya que, en todos los casos, los tribunales emplean el proceso interpretativo con sus etapas para generar sus sentencias y solo después de aplicar las etapas interpretativas se reafirma la aceptación y se fortalece el consenso en torno al paradigma. Lo que sucede es que, al tratarse de conclusiones interpretativas sostenidas en el tiempo, es muy probable que la nueva interpretación del precedente que realice el tribunal de aplicación, arroje un resultado en el mismo sentido que las sentencias previas en tanto los principios de fondo sigan justificando la práctica que se interpreta.

La estabilidad relativa del paradigma contenido en y mantenido por el precedente indica que una conclusión interpretativa permanecerá intacta y será reproducida consistentemente por los tribunales mientras los principios que justificaron la práctica en la sentencia de origen sigan justificando la práctica en los casos subsecuentes. Mientras esto sea así, no hay razón para que los tribunales modifiquen o inapliquen el precedente. Mientras al pasar por el proceso interpretativo, los mismos principios morales sigan

${ }^{111}$ Dworkin, Law's Empire, cit., pp. 72, 89, 92. 
brindando la mejor justificación de la práctica que se interpreta, los tribunales seguirán resolviendo con base en precedentes.

Como se ha visto, la labor interpretativa de los jueces les requiere satisfacer la dimensión de ajuste que consiste precisamente en identificar el material jurídico que constituye la historia institucional de la práctica, ya que su interpretación debe partir de y ajustarse a dicho material. La etapa pre-interpretativa se corresponde con la dimensión de ajuste precisamente porque es en esta etapa donde se reconoce el material que se habrá de justificar, de esta manera, la interpretación que se ofrezca será una interpretación de la práctica que existe y que es reconocida en la historia institucional y no la invención de otra práctica.

En ese sentido, se puede decir que la etapa interpretativa se corresponde con la dimensión de justificación porque en esta etapa se asigna valor a la práctica y se asignan los principios que la justifican de mejor forma. Generalmente, si los principios que mejor justifican la práctica son aquellos reiterados y afianzados por el precedente, la sentencia contará como una más en esa línea. En caso contrario, la dimensión de justificación permitirá identificar cuáles son los principios que mejor justifican la práctica en el momento actual; esto significa que el paradigma afianzado por el precedente ya no proporciona más la mejor justificación de la práctica como lo hizo en el pasado y durante algún tiempo, significa que los principios que sostenían una conclusión interpretativa reiterada ya no son los que brindan la mejor justificación sino que son nuevos principios los que brindan la mejor justificación y por ello, como producto de una nueva interpretación, el antiguo paradigma cae en desuso ante la entrada de un nuevo paradigma.

Este fenómeno provoca a su vez, el desuso de los precedentes que promovieron el antiguo paradigma pues la transformación interpretativa que se experimentó introdujo un cambio de paradigma que brindará a futuro una nueva justificación que a su vez será afianzada a través del precedente y la subsecuente reiteración 
en sede judicial, todo ello para volver a iniciar un nuevo ciclo de estabilidad provisional.

El ciclo de vida de los paradigmas, su uso y desuso se asocia con el precedente ya que éste tiene la virtud de funcionar tanto como un eslabón como un vehículo de cambio en el derecho como integridad. Como eslabón, el precedente promueve la coherencia de principios en el derecho con el uso y reiteración de conclusiones interpretativas (paradigmas). Como vehículo de cambio, cuando así lo demanda una nueva interpretación y se transita hacia un nuevo paradigma, la transformación y modificación está asociada con el pasado, existe una retroalimentación permanente entre la forma que tuvieron las prácticas jurídicas en el pasado, la forma que tienen actualmente y la forma que tendrán.

El derecho como integridad, a la manera de la novela en serie, permanece en la búsqueda permanente de coherencia interna del derecho, de proporcionar respuestas que cuenten una sola historia unificada de la práctica jurídica con sus transformaciones, de tal manera que se advierta como una continuidad en la práctica y no como una ruptura. El precedente facilita las transiciones en esa historia, como eslabones que unen las diferentes etapas que caracterizan la práctica.

\section{Algunas conclusiones y nuevas preguntas}

Como lo propusimos, a lo largo de este trabajo identificamos y elaboramos una reconstrucción de los componentes implícitos y explícitos de la concepción del precedente judicial desde el interpretativismo jurídico de Ronald Dworkin para dar sustancia a la definición provisional que sugerí al inicio del texto, la cual cobra sentido una vez examinados sus componentes.

Lo concepción del precedente interpretativista, es para algunos autores, un ejemplar del modelo de principios, que categoriza las explicaciones teóricas que dan un tratamiento al precedente 
no como reglas, sino como principios. Los modelos que se han sistematizado para dar cuenta del papel que juegan los precedentes en el razonamiento judicial buscan ofrecer una explicación satisfactoria o superior, y la concepción interpretativista ofrece un desarrollo robusto en ese sentido.

La teoría interpretativista de Ronald Dworkin es una postura alternativa muy importante y competitiva a la explicación dominante del concepto de precedente desde el modelo de reglas. El enfoque interpretativista en el concepto de precedente horizontal aporta elementos interesantes para comprender la forma en la que interactúan la historia institucional con el presente y el futuro de las prácticas, esto es, la integridad.

Ahora bien, el enfoque dworkiniano ofrece un tipo particular de explicación normativa que no sólo busca describir cómo es que tradicionalmente se concibe esta labor, sino que pretende indicar cómo debe ser la práctica del precedente y compromete a los tribunales a compromisos morales que den cuenta de la integridad del derecho que aplican.

Finalmente, como el ejemplo más distintivo de la explicación del precedente como modelo de principios, la concepción interpretativista aporta elementos valiosos para la discusión acerca de la mejor manera de entender el precedente judicial que se mantiene en constante evolución.

\section{v. REFERENCIAS BIBLIOGRÁficAS}

Alexander, Larry, "Los jueces como creadores de reglas", Problema. Anuario de Filosofía y Teoría del Derecho, Núm. 4, 2010.

Del Real Alcalá, Juan Alberto, "La decisión judicial según los tipos de casos: clear cases, borderline cases y pivotal cases", Problema. Anuario de Filosofía y Teoría del Derecho, núm. 1, 2007, pp. 394395. 
"The Controversies about Legal Indeterminacy and the Thesis of the 'Norm as a Framework' in Kelsen", European Journal of Legal Studies, Vol. 6, No. 2, Autumn-Winter 20132014, pp. 176, 178.

Dickson, Julie, Evaluación en la teoría del derecho, trad. de Juan Vega Gómez, México, UNAM- Instituto de Investigaciones Jurídicas, 2006.

Duxbury, Neil, The Nature and Authority of Precedent, New York, Cambridge University Press, 2008, pp. 59-60.

Dworkin, Ronald, Taking Rights Seriously, Cambridge, Massachusetts, Harvard University Press, 1977, p. 22.

, Law's Empire, Cambridge, Mass., Belknap-Harvard University Press, 1986.

"Hart's Postcript and the Character of Political Philosophy", Oxford Fournal of Legal Studies, Vol. 24, No. 1, 2004.

EndicotT, Timothy, "Herbert Hart and the Semantic Sting", en Coleman, Jules (ed.), Hart's Postscript. Essays on the Postscript to the Concept of Law, New York, Oxford University Press, 2001, p. 42 .

FLores, Imer B., "The Legacy of Ronald Dworkin (1931-2013): A Legal Theory and Methodology for Hedgehogs, Hercules and One Right Answers", consultado el 20 de octubre de 2020 en http://scholarship.law.georgetown.edu/facpub/1454

Gascón Abellán, Marina, "Motivación de las sentencias y jurisprudencia. ¿Cumple nuestra jurisprudencia su función?, en Marina Gascón Abellán y Álvaro Núñez Vaquero (coords.), La construcción del precedente en el Civil Law, Barcelona, Atelier. Libros jurídicos, 2020. 
Gómora-Juárez, Sandra, "La ejemplaridad y proyección del precedente", Problema. Anuario de Filosofía y Teoría del Derecho, núm. 12, 2018.

, El concepto de precedente, México, UNAM-Instituto de Investigaciones Jurídicas, 2018.

Guest, Stephen, Ronald Dworkin, $3^{\text {rd }}$ ed., Stanford University Press, California, 2013.

Hart, H. L. A., El concepto de derecho, $2^{\mathrm{a}}$ ed., trad. de Genaro R. Carrió, Buenos Aires, Abeledo-Perrot, 1995.

Hershovitz, Scott (ed.), "Integrity and Stare Decisis", Exploring Law's Empire. The Furisprudence of Ronald Dworkin, 2008, p. 114.

Himma, Kenneth, “Trouble in Law's Empire: Rethinking Dworkin's Third Theory of Law", Autumn, 2003, Vol. 23 No. 3, Oxford Journal of Legal Studies.

Jiménez Cano, Roberto M., Fabra Zamora, Jorge Luis y guzmán buelvas, Carolina Esther, "Riggs contra Palmer. Tribunal de Apelaciones de Nueva York - 115 NY 506”, Revista Telemática de Filosofía del Derecho, núm. 11, 2007 /2008, p. 363.

Lamond, Grant, "Precedent and Analogy in Legal Reasoning", The Stanford Encyclopedia of Philosophy (Spring 2016 Edition), Edward N. Zalta (ed.), URL = <https://plato.stanford.edu/archives/ spr2016/entries/legal-reas-prec/>

NúÑez VAquero, Álvaro, "Precedente en materia de hechos", Revista de derecho (Valdivia), Vol. 31, núm.1, julio 2018, consultado el 5 de julio de 2020 en: https://scielo.conicyt.cl/scielo.php?script $=$ sci_ arttextEpid $=$ S0718-09502018000100051 Elng =es Ënrm =iso.

Pannick, David, "A Note on Dworkin and Precedent", Modern Law Review, Vol. 43, Núm. 1, January 1980. 
Postema, Gerald, "Melody and Law's Mindfulness of Time”, Ratio Juris, Vol. 17, No. 2, June 2004, p. 214.

Ramírez Anguiano, Diego, "Derecho, moral e interpretación: correlación entre la filosofía analítica de H. L. A. Hart, el pensamiento de Lon Fuller y Ronald Dworkin”. Problema. Anuario de Filosofía y Teoría del Derecho, núm. 13, 2019.

Sodero, Eduardo, "Sobre el cambio de los precedentes", DOXA. Cuadernos de Filosofia del Derecho 39 (2016).

Solum, Lawrence B., "The Unity of Interpretation”, Boston University Law Review, Vol. 90, No. 2, April 2010, pp. 553-555.

Stavropoulos, Nicos, "Legal Interpretivism", The Stanford Encyclopedia of Philosophy (Summer 2014 Edition), Edward N. Zalta (ed.), URL = <https://plato.stanford.edu/archives/ sum2014/entries/law-interpretivist/>.

Vega Gómez, Juan, "La postura metodológica de Dworkin: lo interesante de la crítica", Ensayos de filosofia jurídica analítica, Madrid, Dykinson, Instituto de Investigaciones JurídicasUNAM, 2014. 